\title{
Association of P2Y12 Gene Promoter DNA Methylation with the Risk of Clopidogrel Resistance in Coronary Artery Disease Patients
}

\author{
Jia Su, ${ }^{1}$ Xiaojing Li, ${ }^{1}$ Qinglin Yu, ${ }^{2}$ Yahui Liu, ${ }^{3}$ Yaqing Wang, ${ }^{3}$ Haojun Song, ${ }^{4}$ \\ Hanbin Cui, ${ }^{1}$ Weiping Du, ${ }^{1}$ Xiaohong Fei, ${ }^{1}$ Junsong Liu, ${ }^{1}$ Shaoyi Lin, ${ }^{1}$ Jian Wang, \\ Wenyuan Zheng, ${ }^{1}$ Jinyan Zhong, ${ }^{1}$ Lulu Zhang, ${ }^{1}$ Maoqing Tong, \\ Jin $X u^{5}$ and Xiaomin Chen ${ }^{1}$ \\ ${ }^{1}$ Department of Cardiology, The Affiliated Ningbo No. 1 Hospital, School of Medicine, Ningbo University, Ningbo, \\ Zhejiang 315010, China \\ ${ }^{2}$ Department of Traditional Chinese Internal Medicine, The Affiliated Ningbo No. 1 Hospital, School of Medicine, Ningbo University, \\ Ningbo, Zhejiang, China \\ ${ }^{3}$ The Key Laboratory of Molecular Medicine, The Affiliated Ningbo No. 1 Hospital, School of Medicine, Ningbo University, \\ Ningbo, Zhejiang, China \\ ${ }^{4}$ Department of Gastroenterology, The Affiliated Ningbo No. 1 Hospital, School of Medicine, Ningbo University, Ningbo, Zhejiang, China \\ ${ }^{5}$ Institute of Preventative Medicine, School of Medicine, Ningbo University, Ningbo, Zhejiang, China
}

Correspondence should be addressed to Jin Xu; xujin1@nbu.edu.cn and Xiaomin Chen; chxmin@hotmail.com

Received 4 January 2014; Revised 10 February 2014; Accepted 10 February 2014; Published 18 March 2014

Academic Editor: Shiwei Duan

Copyright (c) 2014 Jia Su et al. This is an open access article distributed under the Creative Commons Attribution License, which permits unrestricted use, distribution, and reproduction in any medium, provided the original work is properly cited.

Background. Clopidogrel inhibits the ADP receptor P2Y12 to keep down the platelet aggregation. The goal of our study is to investigate the contribution of P2Y12 promoter DNA methylation to the risk of clopidogrel resistance (CR). Methods. The platelet functions were measured by the VerifyNow P2Y12 assay. Applying the bisulfite pyrosequencing technology, DNA methylation levels of two CpG dinucleotides on P2Y12 promoter were tested among 49 CR cases and 57 non-CR controls. We also investigated the association among P2Y12 DNA methylation, various biochemical characteristics, and CR. Result. Lower methylation of two CpGs indicated the poorer clopidogrel response (CpG1, $P=0.009$; CpG2, $P=0.022)$ in alcohol abusing status. Meanwhile CpG1 methylation was inversely correlated with CR in smoking patients $(P=0.026)$ and in subgroup of Albumin $<35(P=0.002)$. We observed that the level of DNA methylation might be affected by some clinical markers, such as TBIL, LEVF, Albumin, AST. The results also showed that the quantity of stent, fasting blood-glucose, and lower $\mathrm{HbACl}$ were the predictors of CR. Conclusions. The evidence from our study indicates that P2Y12 methylation may bring new hints to elaborate the pathogenesis of CR.

\section{Introduction}

ADP activates platelets through two $G$ protein-coupled receptors: $P 2 Y 1$ and $P 2 Y 12$, and the activation of $P 2 Y 12$ leads to sustained platelet aggregation [1]. Clopidogrel inhibits the purinergic ADP receptor P2Y12, keeps down the adenosinediphosphate-induced platelet aggregation, and then prevents the cardiovascular risks in coronary atherosclerotic heart disease $(\mathrm{CAD})$ patients who have been undergoing percutaneous coronary intervention (PCI) [2]. However, the pharmacodynamic response to clopidogrel varies greatly [3], and patients with lesser degrees of platelet inhibition are more likely to suffer ischemic events $[4,5]$.

Clopidogrel resistance (CR) has been used to reflect the failure of clopidogrel to achieve its effect of antiplatelet aggregation. The underlying mechanism remains unclear. The extrinsic or intrinsic factors may contribute to the variability of platelet activity, including the role of genetic polymorphisms of transporters and enzymes participating 
TABLE 1: Primers for P2Y12 gene CpG island loci analysis.

\begin{tabular}{lr}
\hline Group & DNA sequence \\
\hline Forward primer & $5^{\prime}$-AGGAATTTATAGGTTTATAAGTGATGATAT-3' \\
Reverse primer & $5^{\prime}$-Biotin-CCTTCATTATAATTTCTATCCCACTTCTCA-3' \\
Sequencing primer & $5^{\prime}$-GGTTTATAAGTGATGATATTATATG-3 ${ }^{\prime}$ \\
\hline
\end{tabular}

in clopidogrel absorption and metabolic transformation and nongenetic causes, such as drug-drug interactions, comorbidities, and age [6]. Genetic factors, specifically the expression of the gene P2Y12, may play a great role in individual susceptibility to the clopidogrel [7].

DNA methylation is a reliable epigenetic marker and specifically occurs in the context of cytosine-phosphateguanine $(\mathrm{CpG})$ dinucleotide [8]. Vertebrate $\mathrm{CpG}$ islands (CGIs), which are briefly interspersed CpG-rich DNA sequences, are not predominantly methylated in or near the promoters of mammalian genes [9]. CGI hypermethylation is linked to transcriptional silencing of gene expression [10] and thus regulates the level of protein.

The evidence of the association between DNA methylation and the risk of clopidogrel resistance was scarce. Since multiple single-nucleotide polymorphisms (SNPs) associated with poor activity to clopidogrel [11] did not appear to directly affect P2Y12 expression, the altered expression of P2Y12 was likely to be modulated by methylations of promoters or other epigenetic changes. Thus, we attempted to assess whether the DNA methylations of selected CpG islands in P2Y12 gene promoter were involved in clopidogrel resistance. Due to the little knowledge so far, this study may help to explore a novel aspect in understanding the mechanism of clopidogrel resistance.

\section{Methods}

2.1. Study Population. One hundred and six patients with CAD were collected from the Ningbo No. 1 Hospital. All of them were Han Chinese originated from Ningbo city in Eastern China. The inclusion criteria were as follows. (1) Patients for PCI: with drug-eluting stent, PCI was carried out according to current standard guidelines (ACC/AHA guidelines) through the radial route. (2) All the individuals were administrated with a loading dose of aspirin $(300 \mathrm{mg}$ ) as well as clopidogrel (300 mg) before PCI. followed by $75 \mathrm{mg}$ of clopidogrel and $100 \mathrm{mg}$ of aspirin daily. (3) Patients of age $\geq 18$ years and $\leq 80$ years were included. The exclusion criteria were as follows: (1) the administration of concomitant glycoprotein IIb/IIIa inhibitor administration, (2) recent or chronic clopidogrel treatment, (3) sudden death, (4) history of bleeding diathesis, (5) haematocrit $<35 \%$ or $>50 \%$, and (6) total platelet count $<150000 \mu \mathrm{L}$ or $>500000 \mu \mathrm{L}$.

Written informed consent was obtained from all the subjects. The study was approved by the Ethics Committee of Ningbo No. 1 Hospital and conformed with the principles outlined in the Declaration of Helsinki.

2.2. Collection of Samples and Clinical Data. Blood samples were obtained overnight fast from the antecubital vein.
The serologic markers, such as the concentrations of TG, LDL, ALT, AST, and uric acid in plasma, were measured by the IFCC reference measurement systems. All the tests applied the standard procedures recommended by the manufacturers and then the data were collected and entered into a central database.

2.3. Platelet Function Measurements. As there may be no significant changes of platelet reactivity from days 3 to 5 in AMI patients undergoing PCI [4], we measured the patients' platelet reactivity at one week to one month after PCI. Blood samples were collected using the double-syringe technique and the first 2 to $4 \mathrm{~mL}$ free flowing blood was discarded to avoid spontaneous platelet activation. The platelet functions were measured by the VerifyNow P2Y12 assay (Accumetrics Inc., San Diego, CA).

The VerifyNow P2Y12 Assay is a whole blood, pointof-care system that has been developed to evaluate the responsiveness to $P 2 Y 12$ antagonists [12]. Blood is drawn into a Greiner Bio-One 3.2\% citrate Vacuette tube (Greiner BioOne, Kremsmünster, Austria). The assay instrument contains fibrinogen-coated polystyrene beads, $20 \mathrm{nmol} / \mathrm{L}$ ADP, and $22 \mathrm{nmol} / \mathrm{L}$ PGE1. Surveyed by an optical signal, the result was expressed as $P 2 Y 12$ reaction units (PRU). And a residual platelet reactivity (RPR) cutoff value $\geq 240$ reaction units indicated the existence of clopidogrel resistance [13].

2.4. DNA Methylation Assay. Human genomic DNA was extracted from leucocytes of peripheral blood samples with a commercially available kit (QIAamp DNA Blood Mini Kit, Qiagen, Hilden, Germany). DNA concentrations were quantified by the ultramicronucleic acid ultraviolet tester (NANODROP 1000, Wilmington, USA), and all of them were more than $500 \mathrm{ng} / \mu \mathrm{L}$.

Bisulfite pyrosequencing technology was applied to determine the methylation levels of $2 \mathrm{CpG}$ dinucleotides on the fragment of P2Y12 gene promoter, which combines with sodium bisulfite DNA conversion chemistry (EpiTech Bisulfite Kits; Qiagen), polymerase chain reaction (PCR) amplification (Pyromark PCR Kit; Qiagen), and sequencing by synthesis assay (Pyromark Gold Q24 Reagents; Qiagen) of the target sequence. We selected PyroMark Assay Design software for planning PCR primers. Sequences of the PCR and pyrosequencing primers were described in Table 1.

2.5. Statistical Analysis. All data for continuous variables were described as means \pm standard deviation and skewed variables as the median with interquartile range (IQR). A series of statistical analyses were performed to investigate 
TABLE 2: Characteristics comparison between CR and non-CR.

\begin{tabular}{|c|c|c|c|}
\hline & Cases $(n=49)$ & Controls $(n=57)$ & $P$ value \\
\hline Male gender, $n(\%)$ & $35(71.43)$ & $46(80.70)$ & 0.262 \\
\hline Hypertension, $n(\%)$ & $36(73.47)$ & $36(63.16)$ & 0.257 \\
\hline Diabetes mellitus, $n(\%)$ & $10(20.41)$ & $13(22.81)$ & 0.765 \\
\hline Dyslipidemia, $n(\%)$ & $20(40.82)$ & $26(45.61)$ & 0.619 \\
\hline Current smoking, $n(\%)$ & $19(38.78)$ & $21(36.84)$ & 0.838 \\
\hline Alcohol abuse & $9(18.37)$ & $10(17.54)$ & 0.912 \\
\hline Age, y & $65.20 \pm 11.50$ & $61.74 \pm 11.11$ & 0.120 \\
\hline $\mathrm{BMI}, \mathrm{kg} / \mathrm{m}^{2}$, & $23.84 \pm 2.86$ & $24.05 \pm 2.74$ & 0.695 \\
\hline Number of stents per patient & $1.55 \pm 0.98$ & $1.28 \pm 0.77$ & 0.116 \\
\hline Left ventricular ejection fraction, $\%$ & $59.04 \pm 10.07$ & $61.75 \pm 7.45$ & 0.115 \\
\hline Total cholesterol, mg/dL & $4.57 \pm 1.24$ & $4.80 \pm 1.36$ & 0.382 \\
\hline Triglycerides, mg/dL & $1.70 \pm 1.02$ & $1.73 \pm 1.30$ & 0.907 \\
\hline HDL cholesterol, mg/dL & $0.95 \pm 0.23$ & $0.98 \pm 0.31$ & 0.608 \\
\hline LDL cholesterol, mg/dL & $2.81 \pm 1.06$ & $2.96 \pm 0.99$ & 0.459 \\
\hline GLU, $\mathrm{mmol} / \mathrm{L}$ & $6.12 \pm 2.42$ & $5.69 \pm 1.75$ & 0.284 \\
\hline HbAlc, $\%$ & $6.23 \pm 1.31$ & $6.22 \pm 1.42$ & 0.972 \\
\hline ALT, umol/L & $39.67 \pm 32.75$ & $38.95 \pm 31.56$ & 0.908 \\
\hline AST, umol/L & $125.27 \pm 183.75$ & $126.30 \pm 183.16$ & 0.977 \\
\hline TBIL, umol/L & $15.54 \pm 9.21$ & $14.35 \pm 7.42$ & 0.464 \\
\hline Albumin (A), g/L & $37.73 \pm 5.03$ & $39.95 \pm 5.02$ & 0.026 \\
\hline $\mathrm{BUN}, \mathrm{mmol} / \mathrm{L}$ & $5.83 \pm 2.10$ & $5.61 \pm 2.30$ & 0.618 \\
\hline CREA, $\mathrm{mmol} / \mathrm{L}$ & $72.53 \pm 20.33$ & $71.56 \pm 20.06$ & 0.807 \\
\hline $\mathrm{UA}, \mathrm{umol} / \mathrm{L}$ & $342.71 \pm 102.48$ & $321.26 \pm 84.86$ & 0.241 \\
\hline hsCRP, mg/L & $10.13 \pm 17.91$ & $12.00 \pm 21.95$ & 0.636 \\
\hline PLT, $* 10^{9} / \mathrm{L}$ & $191.22 \pm 61.93$ & $208.35 \pm 85.68$ & 0.248 \\
\hline MPV, fL & $8.47 \pm 1.40$ & $8.03 \pm 0.89$ & 0.058 \\
\hline PCT, \% & $0.16 \pm 0.04$ & $0.17 \pm 0.05$ & 0.375 \\
\hline PDW, \% & $16.37 \pm 0.63$ & $16.32 \pm 0.52$ & 0.664 \\
\hline P2Y12 CpG1, (\%) & $43.31 \pm 10.96$ & $44.89 \pm 9.26$ & 0.420 \\
\hline P2Y12 CpG2, (\%) & $37.00 \pm 7.52$ & $37.32 \pm 6.82$ & 0.821 \\
\hline
\end{tabular}

the association among P2Y12 DNA methylation, various biochemical characteristics, and clopidogrel resistance.

For analysis of the association between categorical variables, we used either Pearson's chi-square or Fisher's exact test when appropriate. $t$-test or Wilcoxon rank sum test for unpaired samples was applied to compare any continuous variables. The multiple linear regression was implemented to determine the correlation between the promoter DNA methylation of P2Y12 gene and metabolic factors. The interaction of P2Y12 methylation and confounding variables was tested by logistic regression.

A two-tailed $P$ value less than 0.05 was considered to indicate statistical significance. All the statistical analyses above were carried out by PASW Statistics 18.0 software (SPSS, Inc., Somers, NY, USA).

\section{Results}

From October 2012 to October 2013, a total of 106 CAD patients who met the inclusion criteria were recruited in the current association study. Among them, by the VerifyNow
P2Y12 assay, the PRU of 49 patients was more than 240, and they are defined as having poor reactivity to clopidogrel or clopidogrel resistance. As shown in Table 2, the baseline characteristics of the cases and controls in our study were summarized. The clinical characteristics were matching except the Albumin. One with clopidogrel resistance was more likely to have lower Albumin (cases versus controls: $37.73 \pm 5.03$ versus $39.95 \pm 5.02, P=0.026)$.

In this study, we selected a fragment (GRCh37.p13:151103600-151101600) containing 2 CpG dinucleotides. Through bisulfite pyrosequencing assay, we explored the association of P2Y12 gene promoter DNA methylation with clopidogrel resistance. Meanwhile, as shown in Figure 1 and Table 2, our results showed that P2Y12 CpG1 methylation levels were not significantly associated with clopidogrel resistance (cases versus controls (\%): $43.31 \pm 10.96$ versus $44.89 \pm 9.26, P=0.420)$, so as P2Y12 CpG2 (cases versus controls (\%): $37.00 \pm 7.52$ versus $37.32 \pm 6.82, P=0.821)$ too.

We performed a breakdown analysis by clinical characteristics to evaluate whether the methylation levels of 
TABLE 3: Comparison of P2Y12 methylation levels between cases and controls in subgroup of alcohol abuse or not.

\begin{tabular}{|c|c|c|c|c|c|c|}
\hline & \multicolumn{3}{|c|}{ Alcohol abuse } & \multicolumn{3}{|c|}{ No alcohol abuse } \\
\hline & $\begin{array}{c}\text { Cases }(n=9) \\
\text { Mean } \pm \text { s.e. }\end{array}$ & $\begin{array}{c}\text { Controls }(n=10) \\
\text { Mean } \pm \text { s.e. }\end{array}$ & $P$ value & $\begin{array}{c}\text { Cases }(n=40) \\
\text { Mean } \pm \text { s.e. }\end{array}$ & $\begin{array}{c}\text { Controls }(n=47) \\
\text { Mean } \pm \text { s.e. }\end{array}$ & $P$ value \\
\hline P2Y12 CpG1, (\%) & $36.67 \pm 7.25$ & $46.70 \pm 7.42$ & 0.009 & $44.80 \pm 11.17$ & $44.51 \pm 9.63$ & 0.897 \\
\hline P2Y12 CpG2, (\%) & $31.89 \pm 5.18$ & $38.70 \pm 6.48$ & 0.022 & $38.15 \pm 7.53$ & $37.02 \pm 6.93$ & 0.469 \\
\hline
\end{tabular}

TABLE 4: Comparison of P2Y12 methylation levels between cases and controls in subgroup of current smoking or not.

\begin{tabular}{lccccc}
\hline & \multicolumn{3}{c}{ Current smoking } & \multicolumn{2}{c}{ No current smoking } \\
& $\begin{array}{c}\text { Cases }(n=19) \\
\text { Mean } \pm \text { s.e. }\end{array}$ & $\begin{array}{c}\text { Controls }(n=21) \\
\text { Mean } \pm \text { s.e. }\end{array}$ & $P$ value & $\begin{array}{c}\text { Cases }(n=30) \\
\text { Mean } \pm \text { s.e. }\end{array}$ & $\begin{array}{c}\text { Mean } \pm \text { s.e. } \\
P \text { value }\end{array}$ \\
\hline P2Y12 CpG1, (\%) & $38.53 \pm 6.87$ & $44.90 \pm 10.03$ & $\mathbf{0 . 0 2 6}$ & $46.33 \pm 12.05$ & $44.94 \pm 9.04$ \\
P2Y12 CpG2, (\%) & $34.00 \pm 5.30$ & $37.33 \pm 7.35$ & 0.112 & $38.90 \pm 8.15$ & $37.29 \pm 6.70$ \\
\hline
\end{tabular}

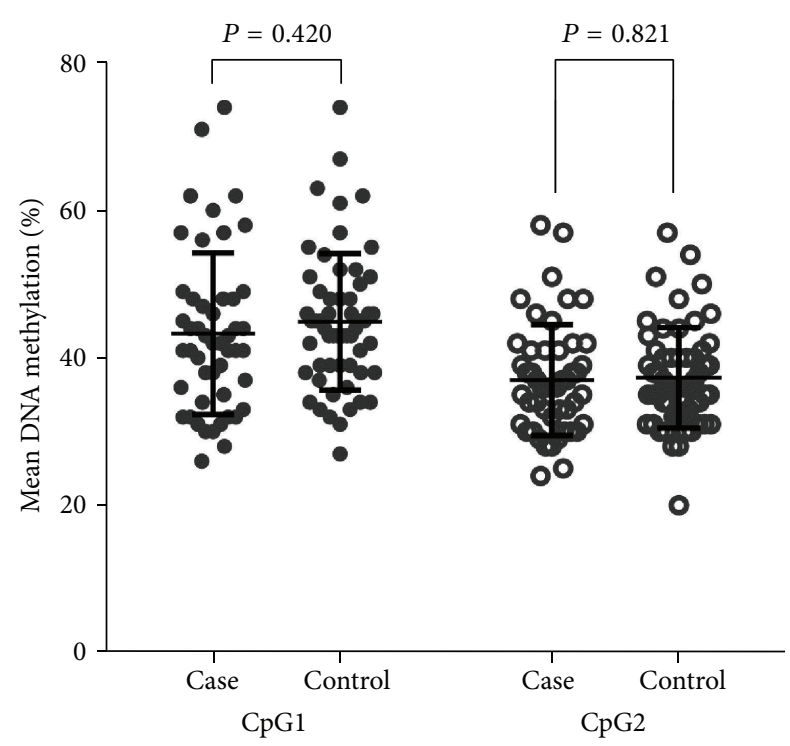

FIGURE 1: Comparison of P2Y12 methylation levels between cases and controls. P2Y12 CpG1 (cases versus controls (\%): $43.31 \pm 10.96$ versus $44.89 \pm 9.26, P=0.420$ ) and P2Y12 CpG2 (cases versus controls (\%): $37.00 \pm 7.52$ versus $37.32 \pm 6.82, P=0.821$ ).

P2Y12 gene promoter (including CpG1 and CpG2) were related to clopidogrel poor response. It became clear to us that a significant association existed in the subgroup of Albumin < 35, current smoking, and alcohol abuse in the present study (Tables 3 to 5). We discovered that if patients were tippling, lower CpG1 (Table 3, cases versus controls (\%): $36.67 \pm 7.25$ versus $46.70 \pm 7.42, P=0.009$ ) and CpG2 (Table 3, cases versus controls (\%): $31.89 \pm 5.18$ versus $38.70 \pm 6.48, P=0.022)$ methylation levels both indicated the poorer clopidogrel response. Moreover, CpG1 methylation was inversely correlated with CR in smoking patients (Table 4 , cases versus controls (\%): $38.53 \pm 6.87$ versus $44.90 \pm 10.03, P=0.026$ ). Similarly, lower levels of P2Y12 CpG1 methylation were notably interrelated with increased risk of CR in subgroup of Albumin < 35 (Table 5, cases versus controls (\%): $34.14 \pm 7.24$ versus $44.70 \pm 4.45, P=0.002$ ).
For the above two effects, no significant interactions were identified in P2Y12 CpG2, and we did not find any other significant association in the rest of the subgroups.

We applied the method of multiple linear regression to explore the effect on DNA methylation from clinical factors. And we observed that the level of DNA methylation might be affected by some clinical marks (Table 6), such as TBIL, LEVF, Albumin, and AST in P2Y12 CpG 1 with alcohol abuse $\left(F=9.302, P_{F \text { value }}=0.001, R\right.$ square $\left.=0.724\right) ;$ LEVF, Albumin, and AST in P2Y12 CpG 2 with alcohol abuse $(F=10.033$, $P_{F \text { value }}=0.001, R$ square $\left.=0.667\right) ;$ LEVF and TBIL in P2Y12 CpG 1 with current smoking $\left(F=6.193, P_{F \text { value }}=0.005, R\right.$ square $=0.251$ ); and LEVF, CRP, BUN, and Triglycerides in P2Y12 CpG 1 with Albumin $<35\left(F=14.345, P_{F \text { value }}<0.001\right.$, $R$ square $=0.840$ ).

Considering the influence of confounding variables, we carried out logistic regression analysis with nongenetic and genetic factors. The result showed that the quantity of stent and fasting blood-glucose were associated with $\mathrm{CR}$, while the $\mathrm{HbACl}$ was inversely correlated with it $(P<0.05$, Table 7$)$. However, if we applied the logistic regression analysis with these in the above subgroups, it was indicated that the above nongenetic and genetic factors were no longer correlated with the poorer clopidogrel response $(P>0.05$, Tables 8,9 , and $10)$.

\section{Discussion}

Since various trails had been keen on the single-nucleotide polymorphisms, some had averted their sight to epigenetics, such as miRNA, DNA methylation. Recently, we have found that aberrant methylation is interpreted to take part in the occurrence and development of diseases including colorectal cancer $[14,15]$, breast cancer $[16,17]$, coronary artery disease [18], and schizophrenia [19]. For clopidogrel resistance, numerous studies have investigated the underlying mechanism. The single-nucleotide polymorphisms (SNPs) within P2Y12 gene have been extensively studied and some research has shown that the $\mathrm{H} 2$ haplotype (the P2Y12 T744C polymorphism) influences the platelet aggregation [11]. Though more studies have paid attention to the epigenetic mechanisms in 
TABLE 5: Comparison of P2Y12 methylation levels between cases and controls in subgroup of Albumin $<35$ or not.

\begin{tabular}{|c|c|c|c|c|c|c|}
\hline & \multicolumn{3}{|c|}{ Albumin $<35$} & \multicolumn{3}{|c|}{ Albumin $\geq 35$} \\
\hline & $\begin{array}{c}\text { Cases }(n=7) \\
\text { Mean } \pm \text { s.e. }\end{array}$ & $\begin{array}{c}\text { Controls }(n=10) \\
\text { Mean } \pm \text { s.e. }\end{array}$ & $P$ value & $\begin{array}{c}\text { Cases }(n=42) \\
\text { Mean } \pm \text { s.e. }\end{array}$ & $\begin{array}{c}\text { Controls }(n=47) \\
\text { Mean } \pm \text { s.e. }\end{array}$ & $P$ value \\
\hline P2Y12 CpG1, (\%) & $34.14 \pm 7.24$ & $44.70 \pm 4.45$ & 0.002 & $44.83 \pm 10.78$ & $44.94 \pm 10.02$ & 0.963 \\
\hline P2Y12 CpG2, (\%) & $31.57 \pm 4.61$ & $35.70 \pm 7.29$ & 0.207 & $37.90 \pm 7.56$ & $37.66 \pm 6.75$ & 0.872 \\
\hline
\end{tabular}

TABLE 6: Multiple linear regression between P2Y12 methylation levels and clinical factors.

\begin{tabular}{|c|c|c|c|c|c|c|}
\hline Model & & $B$ & $P_{\text {coefficients }}$ & $F$ & $P_{F \text { value }}$ & $R$ square \\
\hline \multirow{5}{*}{ P2Y12 CpG1 with alcohol abuse } & (Constant) & 33.069 & 0.012 & 9.302 & 0.001 & 0.724 \\
\hline & TBIL & -0.362 & 0.013 & & & \\
\hline & LEVF & 0.690 & 0.001 & & & \\
\hline & Albumin & -0.755 & 0.019 & & & \\
\hline & AST & 0.017 & 0.050 & & & \\
\hline \multirow{4}{*}{ P2Y12 CpG2 with alcohol abuse } & (Constant) & 21.666 & 0.020 & 10.033 & 0.001 & 0.667 \\
\hline & LEVF & 0.619 & $0.000^{\mathrm{a}}$ & & & \\
\hline & Albumin & -0.668 & 0.010 & & & \\
\hline & AST & 0.017 & 0.014 & & & \\
\hline \multirow{3}{*}{ P2Y12 CpG1 with current smoking } & (Constant) & 28.035 & 0.004 & 6.193 & 0.005 & 0.251 \\
\hline & LEVF & 0.318 & 0.026 & & & \\
\hline & TBIL & -0.314 & 0.049 & & & \\
\hline \multirow{5}{*}{ P2Y12 CpG1 with Albumin $<35$} & (Constant) & -19.001 & 0.109 & 14.345 & $0.000^{\mathrm{a}}$ & 0.840 \\
\hline & LEVF & 0.643 & $0.000^{\mathrm{a}}$ & & & \\
\hline & CRP & 0.129 & 0.001 & & & \\
\hline & BUN & 2.228 & 0.006 & & & \\
\hline & Triglycerides & 3.205 & 0.044 & & & \\
\hline
\end{tabular}

${ }^{\mathrm{a}}$ The $P$ value is less than 0.001 .

cardiovascular disease, especially clopidogrel resistance, for example, miRNA [20], there is little research focusing on the relationship between DNA methylation and the risk of clopidogrel resistance.

In this study, the relationship between P2Y12 gene promoter DNA methylation and the risk of clopidogrel resistance in CAD patients was investigated. As far as we know, it was the first study on the topic of DNA methylation and clopidogrel resistance. Unfortunately, no correlation in selected $\mathrm{CpG}$ islands was detected. However, we found that a significant association existed in the subgroup of Albumin $<35$, current smoking, and alcohol abuse. The lower the methylation levels of CpG1 in the above subgroup, the higher the platelet activity after standardized antiplatelet treatment, similar to the methylation levels of CpG2 in alcohol abuse group too.

Although no public evidence had shown the value of Albumin and alcohol abuse would influence the clopidogrel responding, a new meta-analysis reported that the clinical benefit of clopidogrel treatment in reducing cardiovascular events (including death, myocardial infarction, and stroke) was discovered primarily in smokers, with little benefit in nonsmokers [21]. Thus, we need to give careful consideration to these factors. However, not every study demonstrated the significant association, especially the smoking status receiving clopidogrel. The basic research of their in-depth mechanism, which did not have a definite conclusion, should continue in order to give us ongoing insights.

Additionally, we have to observe the influence of confounding variables on methylation. In our study, some clinical factors (e.g., TBIL, LEVF, Albumin, AST CRP, BUN, and Triglycerides) may influence the level of methylation in a particular population, though the $R$ square in model of $P 2 Y 12$ CpG 1 with current smoking was lower which indicates a lack of reliability. It was similar to other research that the concentration of AST was inversely correlated with ADD1 CpG2-5 methylation levels in female nonessential hypertension [22], and the level of methylation in gene-specific DNA is associated with serum levels of C-reactive protein [23] as well as the levels of Triglycerides and fatty acids in abdominal adipose tissue [24]. However, of all research above including our study, the sample was limited. Additional and larger studies would enhance reliability.

Furthermore, we should focus on the gene-environment interaction. Increasing evidence manifested that environmental and lifestyle factors could influence epigenetic mechanisms, though few were involved in cardiology. For instance, one recent study, which evaluated global DNA methylation from buccal cells of children exposed to smoking, demonstrated hypomethylation of LINE-1 repetitive elements [25]. Another one pointed out that the acute exposure to ethanol 
TABLE 7: Logistic regression analysis with nongenetic and genetic factors in total population.

\begin{tabular}{|c|c|c|c|c|}
\hline Variables & $B$ & $P$ value & $\operatorname{Exp}(B)$ & 95\% C.I. \\
\hline P2Y12 CpG1 & -0.141 & 0.096 & 0.869 & $0.74-1.03$ \\
\hline P2Y12 CpG2 & 0.169 & 0.142 & 1.184 & $0.95-1.49$ \\
\hline Age & 0.047 & 0.163 & 1.048 & $0.98-1.12$ \\
\hline Gender (male) & -0.591 & 0.399 & 0.554 & $0.14-2.19$ \\
\hline Hypertension & 0.569 & 0.324 & 1.767 & $0.57-5.47$ \\
\hline $\mathrm{DM}$ & -0.979 & 0.282 & 0.376 & $0.06-2.24$ \\
\hline Dyslipidemia & -0.538 & 0.395 & 0.584 & $0.17-2.02$ \\
\hline Current smoking & -0.378 & 0.573 & 0.685 & $0.18-2.55$ \\
\hline Alcohol abuse & 1.010 & 0.214 & 2.746 & $0.56-13.51$ \\
\hline BMI & -0.073 & 0.514 & 0.930 & $0.75-1.16$ \\
\hline Stent & 0.865 & 0.009 & 2.374 & $1.24-4.53$ \\
\hline LEVF & -0.035 & 0.368 & 0.965 & $0.89-1.04$ \\
\hline $\mathrm{TC}$ & 0.093 & 0.847 & 1.097 & $0.43-2.82$ \\
\hline Triglycerides & 0.081 & 0.770 & 1.084 & $0.63-1.86$ \\
\hline $\mathrm{HDL}$ & -1.283 & 0.308 & 0.277 & $0.02-3.27$ \\
\hline LDL & -0.408 & 0.481 & 0.665 & $0.21-2.07$ \\
\hline GLU & 0.681 & 0.013 & 1.976 & $1.15-3.39$ \\
\hline $\mathrm{HbACl}$ & -0.907 & 0.022 & 0.404 & $0.19-0.88$ \\
\hline ALT & -0.009 & 0.541 & 0.992 & $0.97-1.02$ \\
\hline AST & 0.002 & 0.366 & 1.002 & $1.00-1.01$ \\
\hline TBIL & -0.036 & 0.357 & 0.965 & $0.89-1.04$ \\
\hline A & -0.091 & 0.264 & 0.913 & $0.78-1.07$ \\
\hline BUN & -0.161 & 0.292 & 0.851 & $0.63-1.15$ \\
\hline CR & -0.004 & 0.825 & 0.996 & $0.97-1.03$ \\
\hline UA & 0.002 & 0.455 & 1.002 & $1.00-1.01$ \\
\hline CRP & -0.007 & 0.677 & 0.993 & $0.96-1.03$ \\
\hline PLT & 0.008 & 0.712 & 1.008 & $0.97-1.05$ \\
\hline MPV & 0.380 & 0.507 & 1.462 & $0.48-4.50$ \\
\hline PCT & -13.635 & 0.639 & 0.000 & $0.00-6.71 E+18$ \\
\hline PDW & -0.183 & 0.736 & 0.832 & $0.29-2.42$ \\
\hline Constant & 8.480 & 0.469 & 4815.697 & \\
\hline
\end{tabular}

TABLE 8: Logistic regression analysis with nongenetic and genetic factors in subgroup of alcohol abuse.

\begin{tabular}{lcccc}
\hline Variables & $B$ & $P$ value & $\operatorname{Exp}(B)$ & $95 \%$ C.I. \\
\hline P2Y12 CpG 1 & -0.362 & 0.242 & 0.697 & $0.38-1.28$ \\
P2Y12 CpG 2 & 0.087 & 0.841 & 1.091 & $0.47-2.55$ \\
Current smoking & -0.512 & 0.845 & 0.599 & $0.00-101.18$ \\
Albumin & -0.046 & 0.799 & 0.955 & $0.67-1.36$ \\
Stent & -0.549 & 0.567 & 0.578 & $0.09-3.77$ \\
GLU & -0.212 & 0.884 & 0.809 & $0.05-13.84$ \\
HbAC1 & -0.134 & 0.943 & 0.875 & $0.02-34.27$ \\
Constant & 17.144 & 0.134 & $2.789 E+07$ & \\
\hline
\end{tabular}

induced high methylation level of specific cell cycle genes in monolayer cultures of neural stem cells [26]. In our study, beside the relationship between P2Y12 gene methylation and the risk of clopidogrel resistance, we could not ignore the gene-environment interaction. Due to such a high interference factor, we wish to apply the multifactor dimensionality
TABLE 9: Logistic regression analysis with nongenetic and genetic factors in subgroup of current smoking.

\begin{tabular}{lcccc}
\hline Variables & $B$ & $P$ value & $\operatorname{Exp}(B)$ & 95\% C.I. \\
\hline P2Y12 CpG 1 & -0.107 & 0.056 & 0.898 & $0.81-1.00$ \\
Alcohol abuse & 0.291 & 0.707 & 1.338 & $0.29-6.12$ \\
Albumin & -0.088 & 0.241 & 0.916 & $0.79-1.06$ \\
Stent & 0.430 & 0.328 & 1.537 & $0.65-3.64$ \\
GLU & 0.577 & 0.150 & 1.781 & $0.81-3.91$ \\
HbAC1 & -0.847 & 0.128 & 0.429 & $0.14-1.28$ \\
Constant & 8.942 & 0.039 & 7648.274 & \\
\hline
\end{tabular}

reduction (MDR), stratified analysis, and crossover analysis to identify and characterize the effect among the P2Y12 methylation and the nongenetic factors [27]. However, it is too difficult to stratify the level of methylation in accepted standards.

Meanwhile, a large quantity of research indicates that some other extrinsic factors, comorbidities, for instance, 
TABLE 10: Logistic regression analysis with nongenetic and genetic factors in subgroup of Albumin $<35$.

\begin{tabular}{lcccc}
\hline Variables & $B$ & $P$ value & $\operatorname{Exp}(B)$ & $95 \%$ C.I. \\
\hline P2Y12 CpG 1 & -0.414 & 0.199 & 0.661 & $0.35-1.24$ \\
Current smoking & -9.623 & 0.922 & 0.000 & $0.00-2.95 E+79$ \\
Alcohol abuse & 4.505 & 0.965 & 90.429 & $0.00-9.00 E+89$ \\
Stent & 0.803 & 0.711 & 2.233 & $0.03-157.51$ \\
GLU & -2.065 & 0.340 & 0.127 & $0.00-8.79$ \\
HbAC1 & 1.789 & 0.573 & 5.986 & $0.01-3041.06$ \\
Albumin & -1.016 & 0.307 & 0.362 & $0.05-2.55$ \\
Constant & 49.113 & 0.265 & $2.136 E+21$ & \\
\hline
\end{tabular}

might also contribute to clopidogrel resistance. We used the logistic regression analysis with confounding factors. In the total population, the quantity of stent, fasting blood-glucose, and lower $\mathrm{HbACl}$ were the predictors of CR. However, if we applied the logistic regression analysis in subgroups (Albumin $<35$, current smoking, and alcohol abuse), all of them, including genetic and nongenetic causes, association were not found. Comorbidities, such as diabetes mellitus (including the type of diabetes [28] and glycemic control [29]), chronic renal diseases [30] or different renal function grades [31], obesity [31] or elevated body mass index (BMI), heart failure [13], and inflammatory state [32], might be the predictor of poor clopidogrel response. Some of the evidence above was similar to ours. Nevertheless, we observed that lower HbAC1 was the predictor of CR. It was opposite to recent studies of evidence-based medicine [33,34]. This may be due to the limited samples and the lack of more consistent stratification. Additionally, a larger sample set of the population and more meticulous stratification standards would help us obtain a comprehensive understanding. Furthermore, as coexisting polymorphisms in different genes might lead to persistent platelet activation while on clopidogrel [35], sophisticated gene-gene interaction of DNA methylation, such as the DNA methylation in $A B C B 1$ or CYP2C19 with P2Y12, also needs to be considered carefully. If future research is possible, the observations will likely bring new information to elaborate the pathogenesis of clopidogrel resistance.

Although considerable efforts have been made, there are some limitations inherent in our study. Firstly, the sample size is relatively small. Future investigation with larger samples can be arranged for further assessment. Secondly, for the whole promoter of P2Y12 gene, we only selected one fragment of the CGI, but there might be other fragments related to clopidogrel resistance. Thirdly, P2Y12 gene methylation was measured in DNA from the leucocyte in peripheral blood which contained granulocytes, lymphocytes, and so on. Fourthly, a possibility of unknown confounding factors might exist and affect the expression of P2Y12 gene methylation. The exact interactions among them remain to be explored in future studies.

In summary, our study indicates that lower P2Y12 gene promoter DNA methylation increases the risk of clopidogrel resistance in the patients with Albumin $\leq 35$, current smoking, or alcohol abuse. Meanwhile some extrinsic factors might be correlated with DNA methylation, and the quantity of stent, fasting blood-glucose, and lower $\mathrm{HbACl}$ might be the predictors of clopidogrel resistance. Thus, we would aim for additional, larger studies and a more advanced empirical approach along with standardized stratification to validate our findings in further cases.

\section{Conflict of Interests}

The authors declare that there is no conflict of interests regarding the publication of this paper.

\section{Authors' Contribution}

Jia Su, Hanbin Cui, Jin Xu, and Xiaomin Chen contributed to the conception of the study; Jia Su, Xiaojing Li, Weiping Du, Xiaohong Fei, Junsong Liu, Shaoyi Lin, Jian Wang, Wenyuan Zheng, Jinyan Zhong, and Lulu Zhang helped with sample and data collection; Jia Su, Xiaojing Li, Yahui Liu, Yaqing Wang, and Maoqing Tong performed the platelet function measurement and bisulfite pyrosequencing; Jia Su, Qinglin $\mathrm{Yu}$, and Haojun Song carried out the analysis of the data and interpretation of the data. All the authors contributed to the writing, discussion, and approval of the paper.

\section{References}

[1] S. P. Kunapuli, R. T. Dorsam, S. Kim, and T. M. Quinton, "Platelet purinergic receptors," Current Opinion in Pharmacology, vol. 3, no. 2, pp. 175-180, 2003.

[2] R. S. Wright, J. L. Anderson, C. D. Adams et al., "2011 ACCF/AHA focused update of the Guidelines for the Management of Patients with Unstable Angina/Non-ST-Elevation Myocardial Infarction (updating the 2007 guideline): a report of the American College of Cardiology Foundation/American Heart Association Task Force on Practice Guidelines developed in collaboration with the American College of Emergency Physicians, Society for Cardiovascular," Journal of the American College of Cardiology, vol. 57, no. 19, pp. 1920-1959, 2011.

[3] P. A. Gurbel, K. P. Bliden, B. L. Hiatt, and C. M. O’Connor, "Clopidogrel for coronary stenting: response variability, drug resistance, and the effect of pretreatment platelet reactivity," Circulation, vol. 107, no. 23, pp. 2908-2913, 2003.

[4] S. Matetzky, B. Shenkman, V. Guetta et al., "Clopidogrel resistance is associated with increased risk of recurrent atherothrombotic events in patients with acute myocardial infarction," Circulation, vol. 109, no. 25, pp. 3171-3175, 2004.

[5] W. Hochholzer, D. Trenk, H.-P. Bestehorn et al., "Impact of the degree of peri-interventional platelet inhibition after loading with clopidogrel on early clinical outcome of elective coronary stent placement," Journal of the American College of Cardiology, vol. 48, no. 9, pp. 1742-1750, 2006.

[6] M. Karaźniewicz-Łada, D. Danielak, and F. Główka, "Genetic and non-genetic factors affecting the response to clopidogrel therapy," Expert Opinion on Pharmacotherapy, vol. 13, no. 5, pp. 663-683, 2012.

[7] G. Campo, L. Fileti, M. Valgimigli et al., "Poor response to clopidogrel: current and future options for its management," Journal of Thrombosis and Thrombolysis, vol. 30, no. 3, pp. 319331, 2010. 
[8] A. Razin, C. Webb, M. Szyf et al., "Variations in DNA methylation during mouse cell differentiation in vivo and in vitro," Proceedings of the National Academy of Sciences of the United States of America, vol. 81, no. 8, pp. 2275-2279, 1984.

[9] M. Fatemi, M. M. Pao, S. Jeong et al., "Footprinting of mammalian promoters: use of a CpG DNA methyltransferase revealing nucleosome positions at a single molecule level," Nucleic Acids Research, vol. 33, no. 20, pp. el76.1-el76.9, 2005.

[10] S. Morita, R. U. Takahashi, R. Yamashita et al., "Genome-wide analysis of DNA methylation and expression of microRNAs in breast cancer cells," International Journal of Molecular Sciences, vol. 13, no. 7, pp. 8259-8272, 2012.

[11] T. Cuisset, C. Frere, J. Quilici et al., "Role of the T744C polymorphism of the $\mathrm{P} 2 \mathrm{Y} 12$ gene on platelet response to a 600-mg loading dose of clopidogrel in 597 patients with nonST-segment elevation acute coronary syndrome," Thrombosis Research, vol. 120, no. 6, pp. 893-899, 2007.

[12] I.-S. Kim, Y.-H. Jeong, M.-K. Kang et al., "Correlation of high post-treatment platelet reactivity assessed by light transmittance aggregometry and the VerifyNow P2Y12 assay," Journal of Thrombosis and Thrombolysis, vol. 30, no. 4, pp. 486-495, 2010.

[13] R. Marcucci, A. M. Gori, R. Paniccia et al., "Cardiovascular death and nonfatal myocardial infarction in acute coronary syndrome patients receiving coronary stenting are predicted by residual platelet reactivity to ADP detected by a point-of-care assay a 12-month follow-up," Circulation, vol. 119, no. 2, pp. 237242, 2009.

[14] R. Grützmann, B. Molnar, C. Pilarsky et al., "Sensitive detection of colorectal cancer in peripheral blood by septin 9 DNA methylation assay," PLoS ONE, vol. 3, no. 11, Article ID e3759, 2008.

[15] T. DeVos, R. Tetzner, F. Model et al., "Circulating methylated SEPT9 DNA in plasma is a biomarker for colorectal cancer," Clinical Chemistry, vol. 55, no. 7, pp. 1337-1346, 2009.

[16] H. M. Müller, H. Fiegl, A. Widschwendter, and M. Widschwendter, "Prognostic DNA methylation marker in serum of cancer patients," Annals of the New York Academy of Sciences, vol. 1022, pp. 44-49, 2004.

[17] H. M. Müller, A. Widschwendter, H. Fiegl et al., "DNA methylation in serum of breast cancer patients: an independent prognostic marker," Cancer Research, vol. 63, no. 22, pp. 76417645, 2003.

[18] S.-P. Guay, D. Brisson, J. Munger, B. Lamarche, D. Gaudet, and L. Bouchard, "ABCA1 gene promoter DNA methylation is associated with HDL particle profile and coronary artery disease in familial hypercholesterolemia," Epigenetics, vol. 7, no. 5, pp. 464-472, 2012.

[19] H. Xu, B. Wang, D. Su et al., "The DNA methylation profile of PLA2G4C gene promoter in schizophrenia," Psychiatry Research, vol. 200, no. 2-3, pp. 1079-1081, 2012.

[20] R. Shi, L. Ge, X. Zhou et al. et al., "Decreased platelet miR223 expression is associated with high on-clopidogrel platelet reactivity," Thrombosis Research, vol. 131, no. 6, pp. 508-513, 2013.

[21] J. J. Gagne, K. Bykov, N. K. Choudhry, T. J. Toomey, J. G. Connolly, and J. Avorn, "Effect of smoking on comparative efficacy of antiplatelet agents: systematic review, meta-analysis, and indirect comparison," British Medical Journal, vol. 347, Article ID f5307, 2013.

[22] L. N. Zhang, P. P. Liu, L. Wang et al., "Lower ADD1 gene promoter DNA methylation increases the risk of essential hypertension," PloS ONE, vol. 8, no. 5, Article ID e63455, 2013.
[23] Y. V. Sun, A. Lazarus, J. A. Smith et al., "Gene-specific DNA methylation association with serum levels of C-reactive protein in African Americans," PloS ONE, vol. 8, no. 8, Article ID e73480, 2013.

[24] S. Gehrke, B. Brueckner, A. Schepky et al., "Epigenetic regulation of depot-specific gene expression in adipose tissue," PloS ONE, vol. 8, no. 12, Article ID e82516, 2013.

[25] C. V. Breton, H.-M. Byun, M. Wenten, F. Pan, A. Yang, and F. D. Gilliland, "Prenatal tobacco smoke exposure affects global and gene-specific DNA methylation," American Journal of Respiratory and Critical Care Medicine, vol. 180, no. 5, pp. 462-467, 2009.

[26] S. D. Hicks, F. A. Middleton, and M. W. Miller, "Ethanolinduced methylation of cell cycle genes in neural stem cells," Journal of Neurochemistry, vol. 114, no. 6, pp. 1767-1780, 2010.

[27] A. A. Motsinger and M. D. Ritchie, "The effect of reduction in cross-validation intervals on the performance of multifactor dimensionality reduction," Genetic Epidemiology, vol. 30, no. 6, pp. 546-555, 2006.

[28] B. Gaborit, C. FrèRe, T. Cuisset, M.-C. Alessi, and A. Dutour, "Enhanced post-clopidogrel platelet reactivity in diabetic patients is independently related to plasma fibrinogen level but not to glycemic control," Journal of Thrombosis and Haemostasis, vol. 7, no. 11, pp. 1939-1941, 2009.

[29] W. Kuliczkowski, M. Gasior, D. Pres et al., "Effect of glycemic control on response to antiplatelet therapy in patients with diabetes mellitus and ST-segment elevation myocardial infarction," American Journal of Cardiology, vol. 110, no. 3, pp. 331-336, 2012.

[30] S. H. Park, W. Kim, C. S. Park, W. Y. Kang, S. H. Hwang, and W. Kim, "A comparison of clopidogrel responsiveness in patients with versus without chronic renal failure," American Journal of Cardiology, vol. 104, no. 9, pp. 1292-1295, 2009.

[31] C. Muller, S. Caillard, L. Jesel et al., "Association of estimated GFR with platelet inhibition in patients treated with clopidogrel," American Journal of Kidney Diseases, vol. 59, no. 6, pp. 777-785, 2012.

[32] D.-W. Park, S.-W. Lee, S.-C. Yun et al., "A point-of-care platelet function assay and C-reactive protein for prediction of major cardiovascular events after drug-eluting stent implantation," Journal of the American College of Cardiology, vol. 58, no. 25, pp. 2630-2639, 2011.

[33] T. Geisler, K. Mueller, S. Aichele et al., "Impact of inflammatory state and metabolic control on responsiveness to dual antiplatelet therapy in type 2 diabetics after PCI: prognostic relevance of residual platelet aggregability in diabetics undergoing coronary interventions," Clinical Research in Cardiology, vol. 99, no. 11, pp. 743-752, 2010.

[34] O. Morel, S. El Ghannudi, S. Hess et al., "The extent of P2Y12 inhibition by clopidogrel in diabetes mellitus patients with acute coronary syndrome is not related to glycaemic control: roles of white blood cell count and body weight," Thrombosis and Haemostasis, vol. 108, no. 2, pp. 338-348, 2012.

[35] L. A. Malek, B. Kisiel, M. Spiewak et al., "Coexisting polymorphisms of $\mathrm{P} 2 \mathrm{Y} 12$ and $\mathrm{CYP} 2 \mathrm{C} 19$ genes as a risk factor for persistent platelet activation with clopidogrel," Circulation Journal, vol. 72, no. 7, pp. 1165-1169, 2008. 


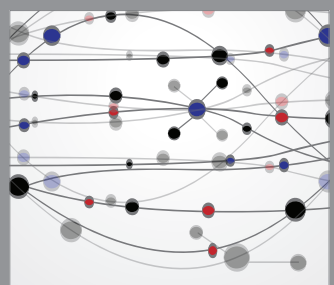

The Scientific World Journal
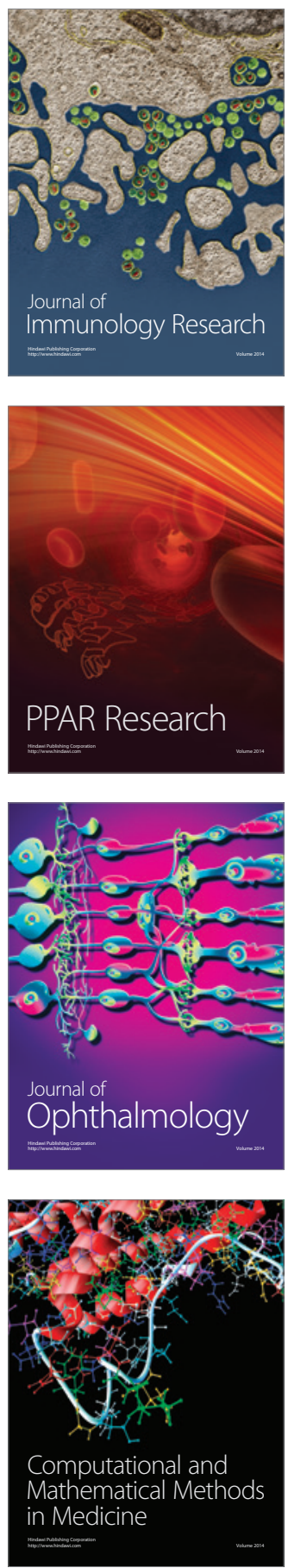

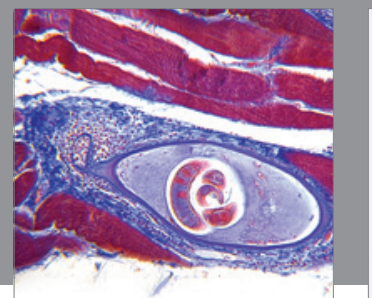

Gastroenterology

Research and Practice
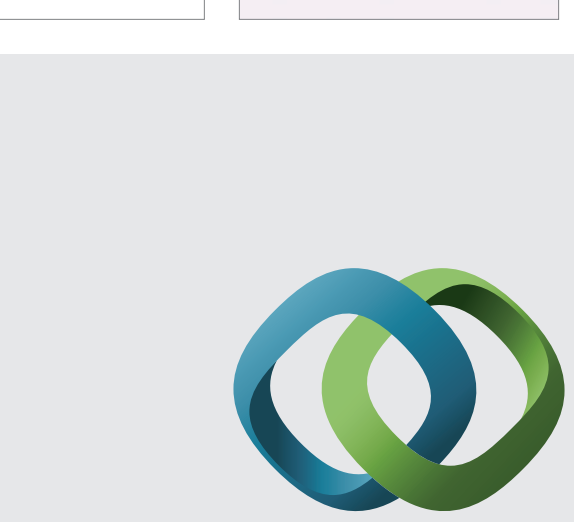

\section{Hindawi}

Submit your manuscripts at

http://www.hindawi.com
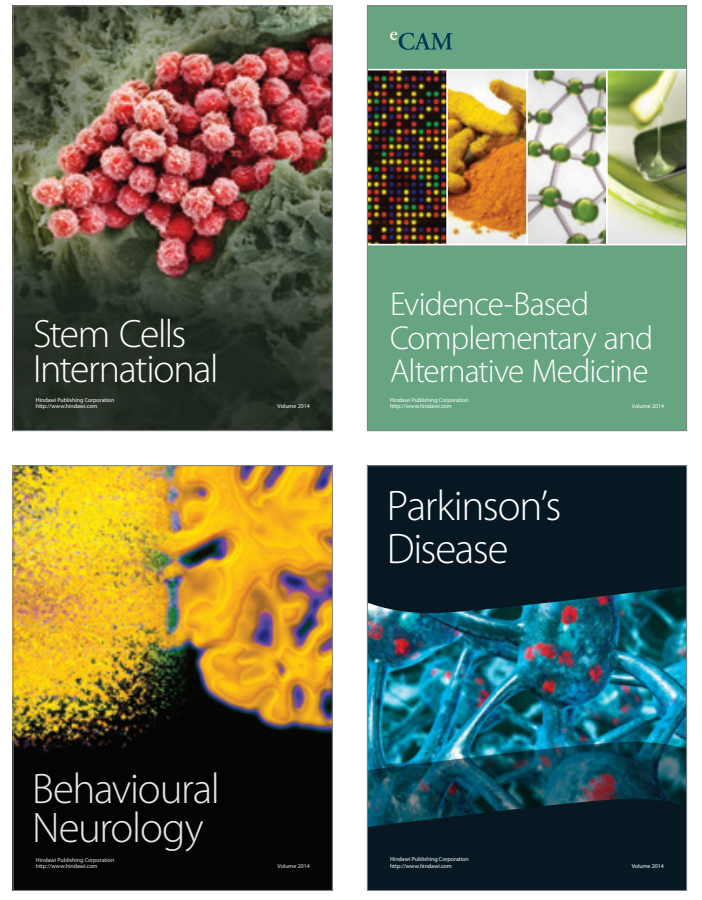
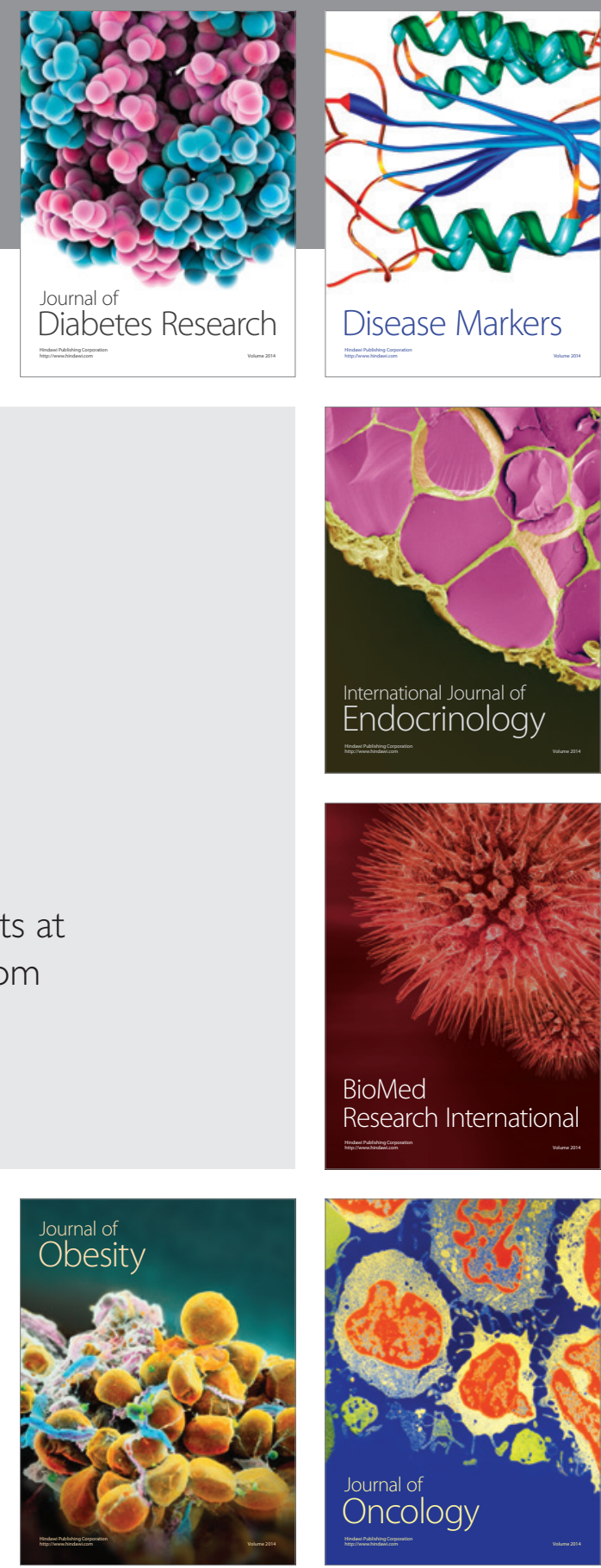

Disease Markers
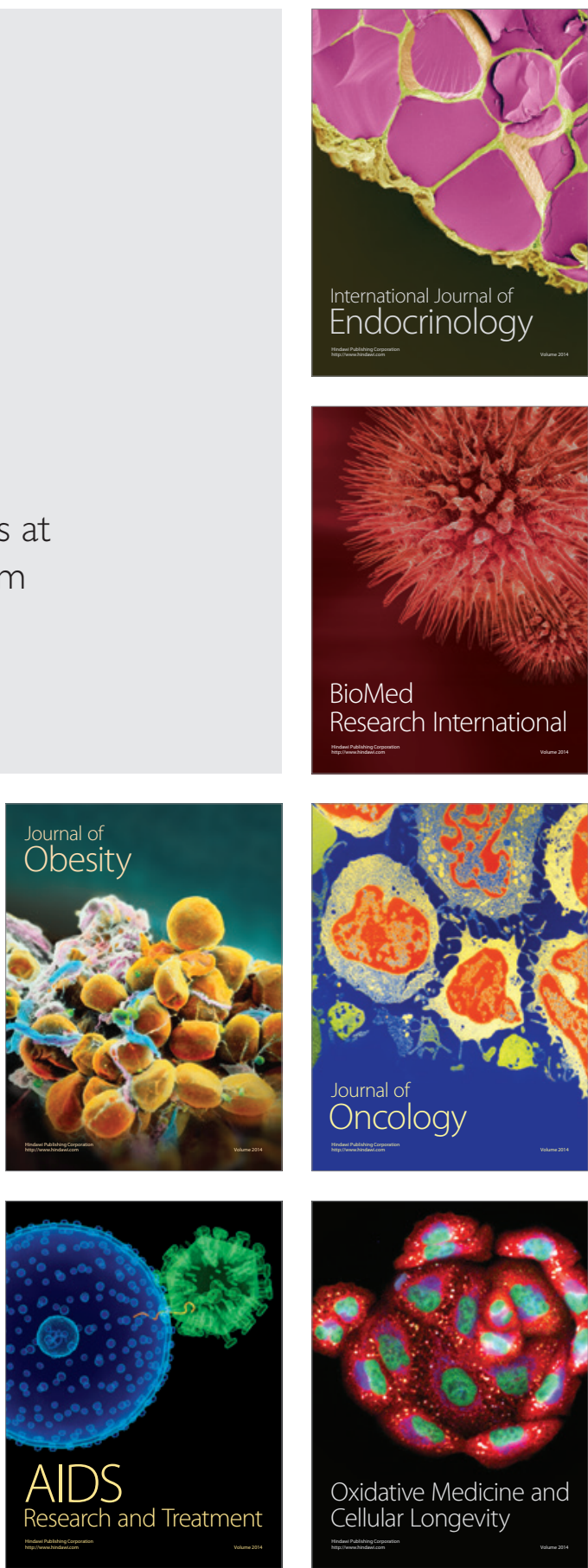